\title{
What can we learn from Global Altimetry/Hydrography comparisons?
}

\author{
Stephanie Guinehut ${ }^{1}$, Pierre-Yves Le Traon ${ }^{2 *}$, Gilles Larnicol ${ }^{1}$
}

\author{
${ }^{1} \mathrm{CLS} /$ Space Oceanography Division, Ramonville Saint-Agne, France \\ ${ }^{2}$ Institut français de recherche pour l'exploitation de la mer (IFREMER), Technopole de Brest-Iroise, Plouzané, \\ France \\ *: Corresponding author : Pierre.Yves.Le.Traon@ifremer.fr
}

\begin{abstract}
Differences and complementarities between altimeter and hydrographic data are studied to describe the sea level and ocean circulation variations in terms of steric and non-steric contributions. Altimeter sea level anomalies (SLA) and hydrographic dynamic height anomalies (DHA) agree remarkably well. They also reveal, however, systematic large-scale differences in several areas of the Pacific and Indian oceans that are related to a barotropic, Sverdrup-like, response of the ocean to wind forcing. In addition, the use of the two data sets provides a good estimation of the partition between barotropic and baroclinic modes needed for data synthesis or assimilation studies.
\end{abstract}

Keywords: Altimetry, Hydrography, Physical Oceanography 


\title{
What can we learn from Global Altimetry/Hydrography comparisons?
}

\author{
Stephanie Guinehut ${ }^{(1)}$, Pierre-Yves Le Traon ${ }^{(2)}$ and Gilles Larnicol ${ }^{(1)}$ \\ ${ }^{(1)}$ CLS - Space Oceanography Division, Ramonville, France \\ ${ }^{(2)}$ IFREMER, Plouzané, France
}

\begin{abstract}
Differences and complementarities between altimeter and hydrographic data are studied to describe the sea level and ocean circulation variations in terms of steric and non-steric contributions. Altimeter sea level anomalies (SLA) and hydrographic dynamic height anomalies (DHA) agree remarkably well. They also reveal, however, systematic large-scale differences in several areas of the Pacific and Indian oceans that are related to a barotropic, Sverdrup-like, response of the ocean to wind forcing. In addition, the use of the two data sets provides a good estimation of the partition between barotropic and baroclinic modes needed for data synthesis or assimilation studies.
\end{abstract}

\section{Introduction}

Altimeter measurements of time variations in the height of the sea surface and in-situ measurements of temperature and salinity profiles are the two most important complementary components of the ocean observing system required by climate and operational oceanography applications (GODAE Strategic Plan, 2001). Both types of data are assimilated in ocean general circulation models to provide integrated 4D descriptions of the ocean state at high temporal and spatial resolution. Since altimeter data includes both steric and non-steric contributions to sea level (e.g. Pattullo et al. 1955; Gill and Niiler, 1973; Stammer, 1997; Fukumori et al., 1998; among others), it is necessary to distinguish these two components to correctly merge altimeter and in-situ data through data assimilation techniques. 
In this paper, the differences and complementarities between sea level anomalies (SLA) deduced from altimeter measurements and dynamic height anomalies (DHA) calculated from in-situ temperature $(\mathrm{T})$ and salinity $(\mathrm{S})$ profiles are investigated to describe the ocean circulation in terms of steric and non-steric contributions to SLA. In particular, the relationship between the two data sets and the barotropic Sverdrup circulation is analyzed and the partition between baroclinic and barotropic modes is described. The study has been performed for the first time globally over the 1993-2003 period. Data and methods are presented in the first section. Results are then discussed. Conclusions are given in the final section.

\section{Data}

The altimeter data used are AVISO delayed-mode products that include merged Topex/Poseidon and ERS-1/2 data from January 1993 to August 2002, merged Jason-1 and ERS-2 data from August 2002 to June 2003 and merged Jason-1 and Envisat data from June 2003 to December 2003 (SSALTO/DUACS User Handbook, 2004). This product provides SLA relative to a 7-year time mean from 1993 to 1999 . It consists of maps produced every seven days on a $1 / 3^{\circ} \times 1 / 3^{\circ}$ Mercator grid using the mapping method detailed in Le Traon et al. (1998) and Ducet et al. (2000).

In-situ T/S profiles come from XBT, CTD and Argo profiling floats (ENACT data base for the years 1993 to 2001, see Ingleby and Huddleston (2005) and CORIOLIS data base for the years 2002 and 2003). As a compromise between the number of data selected and the maximum sampled depth of these data, the reference depth for the analyses was chosen at $700 \mathrm{~m}$. A total of 350000 validated profiles are collected for the 1993-2003 period. Only 90000 profiles are available if the reference depth is taken to be at $1000 \mathrm{~m}$ depth. 


\section{Methods}

Dynamic heights relative to $700 \mathrm{~m}$ depth are first calculated from $\mathrm{T}$ and S profiles. When salinity is missing (as it is for $75 \%$ of the profiles), dynamic heights from $\mathrm{T}$ measurements are estimated by combining $\mathrm{T}$ data with a climatological temperature-salinity or salinity-depth relationship as a function of the geographical position of the measurements. The method used is identical to the one developed by Emery and Dewar (1982) and is based on the monthly mean climatology from the World Ocean Atlas 2001 (WOA01: Conkright et al., 2001).

To calculate anomalies of dynamic height consistent with the altimeter SLA, a synthetic climatology approach is then used. The technique, first applied by Mitchell et al. (1990) consists in combining altimeter SLA with simultaneous in-situ dynamic height to estimate a 7-year mean dynamic height. It allows us to obtain a spatially homogenous mean dynamic height reducing considerably the problems due to the non-uniform temporal and spatial distribution of in-situ measurements. This new mean dynamic height provides an improved comparison when altimeter data are compared with in-situ data. The rms differences between 77000 independent in-situ profiles from the year 2004 and corresponding SLA from combined Jason-1/Envisat altimeter measurements reduced from $6.4 \mathrm{~cm}$ rms if WOA01 mean dynamic height is used to $5.7 \mathrm{~cm} \mathrm{rms}$ with the synthetic climatology.

Finally to compare SLA and DHA, SLA maps are interpolated to the time and location of each insitu DHA measurement using a linear space/time interpolation. This considerably reduces errors due to different sampling characteristics of altimeter and in-situ data.

\section{Consistency between altimeter and in-situ SLA}

One of the main results of this work is the excellent agreement between collocated SLA and DHA. Correlation coefficients between the two time series have been calculated on a $2^{\circ} \times 2^{\circ}$ horizontal grid 
using observations available in $10^{\circ}$ longitude by $2^{\circ}$ latitude radius of influence around each grid point to reduce considerably the problems due to the non-uniform temporal and spatial distribution of in-situ measurements, to take into account the latitudinal structure of the signal and to obtain a relatively large-scale uniform map. They are almost everywhere greater than 0.5 and even greater than 0.7 in most part of the Pacific and Indian oceans (Figure 1).

Time series of collocated SLA and DHA match also each other very well in sign and amplitude for all ocean basins (see Figures A1, A2 and A3 for the time series of SLA and DHA as monthly means and as spatial averages over $10^{\circ}$ of latitude ${ }^{1}$ ). In mid-latitude regions, spatially averaged SLA and DHA show a strong seasonal cycle with similar amplitude which is due to the steric heating and cooling of the upper water column. In the tropics, where the wind changes drive the sea level variability, the response of sea level to wind forcing is also similar in SLA and DHA with a seasonal cycle associated to the equatorial current system (Gill and Niiler, 1973; Stammer, 1997; Fukumori et al., 1998; Vivier et al., 1999).

Although SLA and DHA are very consistent with time at all latitudes bands, systematic differences between the two sets of data can be observed for example in the northern part of the North Pacific Ocean (see Figure A1 and Figure 2). These differences show a well-marked seasonal cycle in different parts of the Pacific and Indian Oceans with amplitude of the order of 3 to $5 \mathrm{~cm}$ with minimum and maximum values in winter and summer. The Atlantic Ocean also shows a seasonal cycle but with a smaller amplitude of $2 \mathrm{~cm}$ and with minimum and maximum values in spring and fall.

Since SLA observe effects of the entire water column and DHA is an estimation of the baroclinic or steric component between the surface and the reference level $(700 \mathrm{~m})$ to change in sea level, the

\footnotetext{
${ }^{1}$ Auxiliary material is available at $\mathrm{ftp}: / / \mathrm{ftp}$.agu.org/apend/gl/?????.
} 
differences between the two data sets can arise from changes in bottom pressure which are directly related to the total mass of the water column (barotropic or non-steric component) or from density changes (baroclinic or steric) with depth below $700 \mathrm{~m}$.

Additionally, as $75 \%$ of the in-situ profiles contain only climatological salinity information, missing measured salinity might also affect the results. The rms differences between 72500 in-situ profiles for which salinities are available and corresponding SLA reduced from $6.93 \mathrm{~cm}$ rms if the climatological salinities are used to $6.62 \mathrm{~cm}$ rms with the in-situ salinities. The rms differences between the two tests thus corresponds to $9.6 \%$ of the SLA minus DHA signal. As steric variability below $700 \mathrm{~m}$ depth may also affect the agreement between SLA and DHA, 40000 relatively deep profiles were used to compare the SLA minus DHA signal using a level of no motion at $700 \mathrm{~m}$ depth and at $1500 \mathrm{~m}$ depth. The rms differences between SLA and DHA reduced from $7.79 \mathrm{~cm}$ rms using a level of no motion at $700 \mathrm{~m}$ to $7.03 \mathrm{~cm}$ rms with $1500 \mathrm{~m}$. The rms differences between the two tests thus corresponds to $18.6 \%$ of the SLA minus DHA signal. This result means that the density changes below $700 \mathrm{~m}$ are much less important than the one above and that as for the climatological salinity, this signal has only a small impact on the SLA minus DHA signal.

\section{Altimeter minus in-situ SLA and the Sverdrup transport}

We now compare the transport implied by SLA minus DHA differences with the wind-driven Sverdrup transport to determine if the (SLA-DHA) signal can be associated to the ocean response to wind forcing (according to a Sverdrup dynamic). The Sverdrup transport $\left(=\int \frac{1}{\rho \beta}\left(\frac{\partial \tau^{y}}{\partial x}-\frac{\partial \tau^{x}}{\partial y}\right) d x\right.$; Pond and Pickard, 1983) is calculated from ERS-1/2 (from 1993 to 1999) and QuickSCAT (from 2000 to 2003) monthly means wind stress fields distributed by Centre ERS d'Archivage et de Traitement (CERSAT, 1996) with the eleven-year (1993-2003) mean removed. 
Correlation coefficients between SLA minus DHA differences and Sverdrup transport anomalies have been calculated at basin-scale using very large influence radius (Figure 3). They show high values $(>0.5-0.7)$ in the South Indian and Pacific Oceans (i.e. between 10 and $\left.30^{\circ} \mathrm{S}\right)$ and in the North Pacific subtropical and subpolar gyres, indicating that the response to wind forcing is deeper and stronger than is revealed by the in-situ data referenced to $700 \mathrm{~m}$ depth. SLA minus DHA differences and Sverdrup transport anomalies time series confirm these results and match each other very well in sign and amplitude in the same regions (see Figures A4, A5 and A6 for the time series of (SLADHA) and Sverdrup transport anomalies as monthly means and as spatial averages over $10^{\circ}$ of latitude) with, in particular, very similar seasonal and inter-annual cycles.

In a similar study to ours, McCarthy et al. (2000) found good agreement between T/P-XBT zonally averaged differences and Sverdrup transport anomalies along repeat hydrographic transects at $32^{\circ} \mathrm{S}$ in the South Pacific subtropical gyre. They suggested a barotropic response, expecting that mass is stored during the gyre spinup because of a lag between the Ekman pumping and the full baroclinic response. They also observed this relation along the XBT transect near $20^{\circ} \mathrm{N}$ across the subtropical gyre of the North Pacific Ocean investigated by Gilson et al. (1998). Isoguchi et al. (1997) also suggest that T/P sea surface height variations (with steric component removed) in the subarctic North Pacific is approximately explained by the time-dependent wind-driven circulation. Stammer (1997) found that SLA are relatively in phase with those of the wind stress curl over most latitudes of the Pacific Ocean after the steric component had been removed from the SLA. As a complement, Chelton and Mestas-Nunez (1997) and Stammer (1997) have stated that the bathymetry of the North Pacific Ocean which is relatively simple allows a Sverdrup balance to take place at the basin scale. Indeed, since Sverdrup equilibrium supposes that the vertical currents at the bottom are null, the Sverdrup balance is much easier established in the Pacific Ocean where the deep thermohaline 
circulation is small. Vivier et al. (1999) also show that a time-varying topographic Sverdrup balance is detectable over vast area of the Pacific Ocean.

The situation in the Atlantic Ocean is much more difficult to analyze. SLA minus DHA differences are very noisy and their amplitudes are lower than the ones observed in the two others ocean basins. Correlation coefficients between (SLA-DHA) differences and Sverdrup transport anomalies time series are very low $(<0.3)$ and (SLA-DHA) differences cannot be explained by a barotropic response, according to a Sverdrup balance, of the Atlantic Ocean to the wind forcing. On the other hand, the thermohaline circulation of the North Atlantic Ocean is important which can involve high vertical currents along topographic features (Cane et al., 1998 ; Cane and Kamenkovich, 1999 ; Mellor, 1999). Since, Sverdrup relation supposes that the currents at the bottom are null, the Sverdrup balance does not seem to be a good representation of the circulation of the Atlantic Ocean. Wunsch and Roemmich (1985) concluded that there was no evidence that the total transport of the North Atlantic Ocean satisfy the Sverdrup relation. Our study seems to indicate that this is also the case for the seasonal variations of the circulation. Wunsch and Roemmich (1985) also suggested that the flows are equally dominated by bottom-induced vertical velocities as they are directly driven by the wind stress curl.

\section{Partition between barotropic and baroclinic modes}

The vertical structure of the ocean is now described using the in-situ and altimeter data sets. To quantify the change of dynamic height at $700 \mathrm{~m}$ depth compared to the change of dynamic height at the surface and also to calculate DHA from SLA, regression coefficients between SLA and DHA have been calculated. Since it has been demonstrated that the density changes below $700 \mathrm{~m}$ are much less important than the one above, this calculation allows us to give a good estimation of the partition 
between barotropic and baroclinic modes needed for the joint assimilation of altimeter and in-situ observations in ocean models.

The spatial structure of these regression coefficients is largely dependant on latitude (Figure 4). In the equatorial regions, the vertical structure of the ocean is mainly baroclinic with regression coefficients between SLA and DHA greater than 0.8. Near the equator, the baroclinic circulation is confined in the first hundred meters of the ocean. In the tropical regions, the vertical structure of the ocean is also baroclinic with regression coefficients of the order of 0.7 . At high latitudes, the vertical structure of the ocean is more barotropic with regression coefficients less than 0.4 . An exception to this latitudinal distribution is found in the South Pacific Ocean between 20 and $30^{\circ} \mathrm{S}$ which shows high correlation values $(>1)$. Theses high values are explained by stronger amplitude DHA than SLA (see Figure A1), the DHA being compensated by the barotropic response to wind forcing (Figure 3).

Spatial structure of the regression coefficients presented on Figure 4 mainly depends on the vertical stratification and on the Coriolis parameter. For a stratified fluid in rotation, the ratio between horizontal scales and vertical scales is of the order of N/f where $\mathrm{N}$ is the Brunt-Väisälä frequency and f the Coriolis parameter (Wunsch, 1982). At high latitude where the stratification is weak and the Coriolis parameter is high, the vertical coupling is high and barotropic flow dominates. Inversely, at low latitudes where the stratification is important and the Coriolis parameter is low, the vertical coupling is reduced and the baroclinic flow dominates. This is observed in current meter records (Wunsch 1997) as well as in Figure 4.

\section{Summary and Conclusions}

The differences and complementarities between SLA and DHA are investigated in order to describe the ocean structure in terms of steric and non-steric contributions to sea level. Results show very 
good correlation between the two data sets. This consistency means that these two complementary data sets can be jointly used in ocean forecasting models or in data synthesis methodologies taking advantage of their complementarities.

Time-varying spatial averages of the differences between SLA and DHA are found to be related to changes in Sverdrup transport in several areas of the Pacific and Indian Oceans. These results mean that the ocean response is deeper and stronger than is revealed by the in-situ data alone and that large-scale seasonal variability of the dynamic height at $700 \mathrm{~m}$ depth is governed by a barotropic response (from a Sverdrup balance) of the ocean to wind forcing in these areas. Additionally, a precise and global estimation of the partition between barotropic and baroclinic modes needed for ocean data synthesis and assimilation is obtained for the first time using only the two data sets (remote-sensing and in-situ). Our results are in agreement with previous works but they have been obtained for the first time at a global scale using a long time series of in-situ and altimeter data.

The present study has been limited by the spatial and temporal repartition of the in-situ observations. With the development of the Argo project (Roemmich, 1999), partition between barotropic and baroclinic modes could now be studied at a seasonal time scale and down to 1000 or $2000 \mathrm{~m}$ depth. Differences and complementarities between altimeter and hydrographic data being better understood, work should now be focused on improving the merging of these two data sets via multivariate multi data assimilation systems to better estimate 4D temperature and salinity fields.

Acknowledgements. The study was carried as part of the French MERCATOR science working team activities (Groupe Mission Mercator) and the European Gyroscope project (EVK2_CT_2000_00087). 


\section{References}

Cane, M. A., V. M. Kamenkovich, and A. Krupitsky, 1998: On the Utility and Disutility of JEBAR, J. Phys. Oceanogr., 28 (3), 519-526.

Cane, M. A., and V. Kamenkovich, 1999: Reply, J. Phys. Oceanogr., 29 (8), 2119.

CERSAT, 1996: Mean Wind Field Atlas user manual handbook, CERSAT/Ifremer, Brest, France.

Chelton, D. B., and A. M. Mestas-Nunez, 1997: The Large-Scale, Wind-Driven Response of the North Pacific, Int. WOCE. Newsl., 25, 3-6.

Conkright, M. E., R. A. Locarnini, H. E. Garcia, T. D. O'Brien, T. P. Boyer, C. Stephens, and J. I. Antonov, 2002: World Ocean Atlas 2001: Objective Analyses, Data Statistics, and Figures, CDROM Documentation. National Oceanographic Data Center, Silver Spring, MD. pp. 17.

Ducet, N., P.-Y. Le Traon, and G. Reverdin, 2000: Global high resolution mapping of ocean circulation from TOPEX/Poseidon and ERS-1/2, J. Geophys. Res., 105 (C8), 19477-19498.

Emery, W. J., and J. S. Dewar, 1982: Mean Temperature-Salinity, Salinity-Depth and TemperatureDepth Curves for the North Atlantic and the North Pacific, Prog. Ocean., 11, 219-305.

Fukumori, I., R. Raghunath, and L.-L. Fu, 1998: Nature of global large-scale sea level variability in relation to atmospheric forcing: A modeling study, J. Geophys. Res., 103 (C3), 5493-5512.

Gill, A.E., and P.P. Niiler, 1973: The theory of the seasonal variability of the ocean, Deep-Sea Res., 20, 141-177.

Gilson, J., D. Roemmich, and B. Cornuelle, 1998: Relationship of TOPEX/Poseidon altimetric height to steric height and circulation in the North Pacific, J. Geophys. Res., 103 (C12), 27947-27965.

GODAE Strategic Plan, 2001. GODAE Report No 6. Published by the GODAE International Project Office, Bureau of Meteorology, Melbourne. pp. 23.

Ingleby, B. and M. Huddleston, 2006: Quality control of ocean profile temperature and salinity profiles - Historical and real-time data, J. Mar. Sys, submitted. 
Isoguchi, O., H. Kawamura, and T. Kono, 1997: A study on wind-driven circulation in the subartic North Pacific using TOPEX/POSEIDON altimeter data, J. Geophys. Res., 102 (C6), 12457-12468.

Le Traon, P.-Y., F. Nadal, and N. Ducet, 1998: An improved mapping method of multisatellite altimeter data, J. Atm. Oc. Tech., 15 (2), 522-534.

McCarthy, M. C., L. D. Talley, and D. Roemmich, 2000: Seasonal to interannual variability from expendable bathythermograph and TOPEX/Poseidon altimeter data in the South Pacific subtropical gyre, J. Geophys. Res., 105 (C8), 19535-19550.

Mellor, G. L., 1999: Comments on "On the utility and disutility of JEBAR", J. Phys. Oceanogr., 29 (8), 2117-2118.

Mitchell, J. L., J. M. Dastugue, W. J. Teague, and Z. R. Hallock, 1990: The estimation of geoid profiles in the northwest Atlantic from simultaneous satellite altimetry and airborne expendable bathythermograph sections, J. Geophys. Res., 95 (C10), 17965-17977.

Pattullo, J., W. Munk, R. Revelle, and E. Strong, 1955: The seasonal oscillation in sea level, J. Mar. Res., 14, 88-155.

Pond, S., and G.L. Pickard, 1983: Introductory Dynamical Oceanography, 329 pp., Butterworth Heinemann.

Roemmich, D., O. Boebel, Y. Desaubies, H. Freeland, B. King, P.-Y. Le Traon, B. Milinari, B. Owens, S. Riser, U. Send, K. Takeuchi, and S. Wijffels, 1999: Argo: The Global Array of Profiling Floats, The Ocean Observing System for Climate, International Symposium, Saint Raphaël, France. SSALTO/DUACS User Handbook, 2004: (M)SLA and (M)ADT Near-Real Time and Delayed Time Products, CLS report 04.103.

Stammer, D., 1997: Steric and wind-induced changes in TOPEX/POSEIDON large-scale sea surface topography observations, J. Geophys. Res., 102 (C9), 20987-21009. 
Vivier, F., K. A. Kelly, and L. Thompson, 1999: Contribution of wind forcing, waves, and surface heating to sea surface height observations in the Pacific Ocean, J. Geophys. Res., 104 (C9), 2076720788.

Wunsch, C., 1982: The ocean circulation and its measurement from space, in Space Oceanology, edited by Cepadues-Editions, pp. 13-67, Toulouse.

Wunsch, C., and D. Roemmich, 1985: Is the North Atlantic in Sverdrup Balance?, J. Phys. Oceanogr., 15, 1876-1880.

Wunsch, C., 1997: The Vertical Partition of Oceanic Horizontal Kinetic Energy, J. Phys. Oceanogr., $27(8), 1770-1794$. 


\section{Figures}

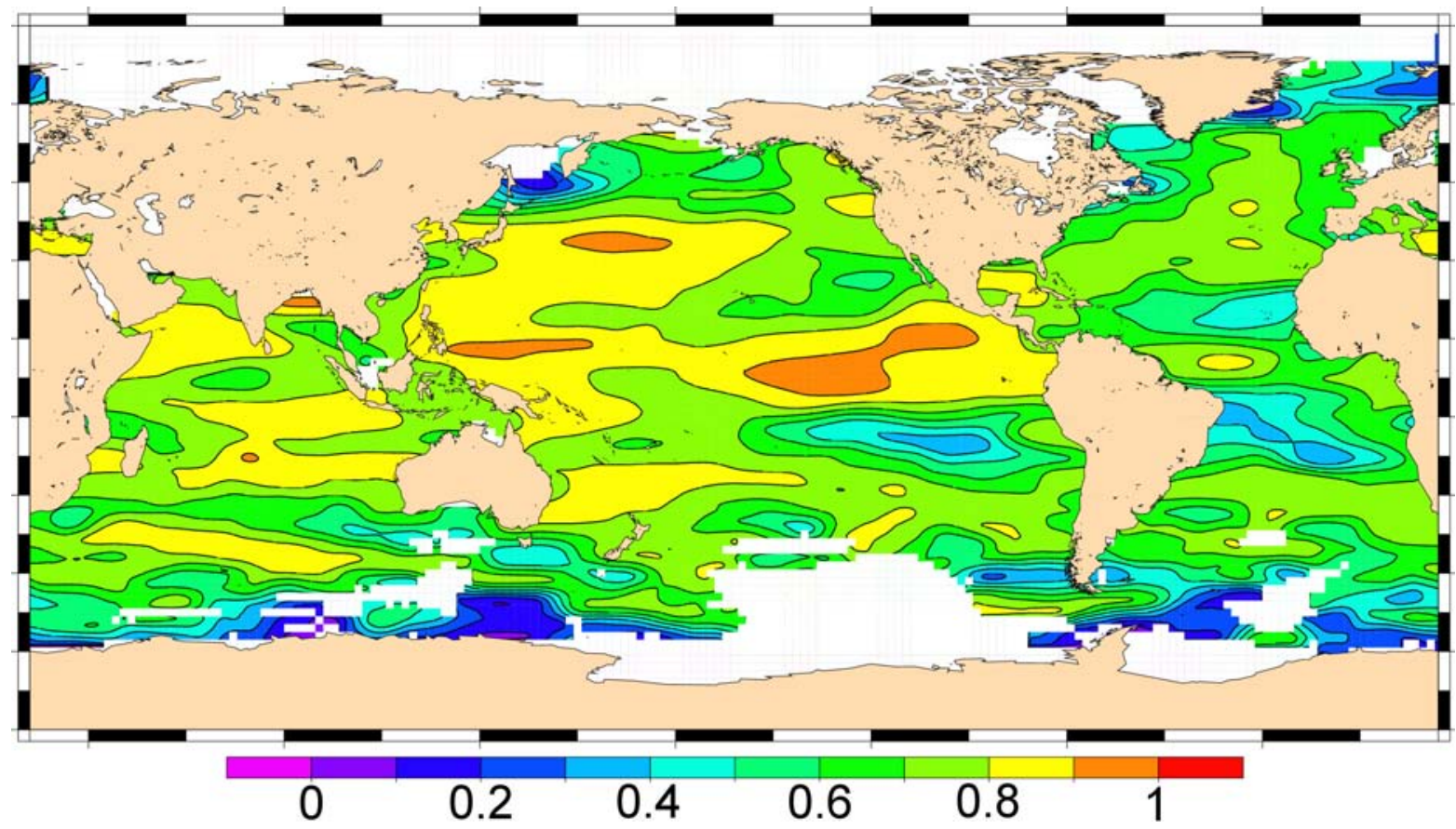

Figure 1: Correlation coefficient between SLA and DHA. Statistics have been calculated on a $2^{\circ} \times 2^{\circ}$ horizontal grid using observations available in $10^{\circ}$ longitude by $2^{\circ}$ latitude radius of influence around each grid point. Boxes with less than 20 observations are masked.

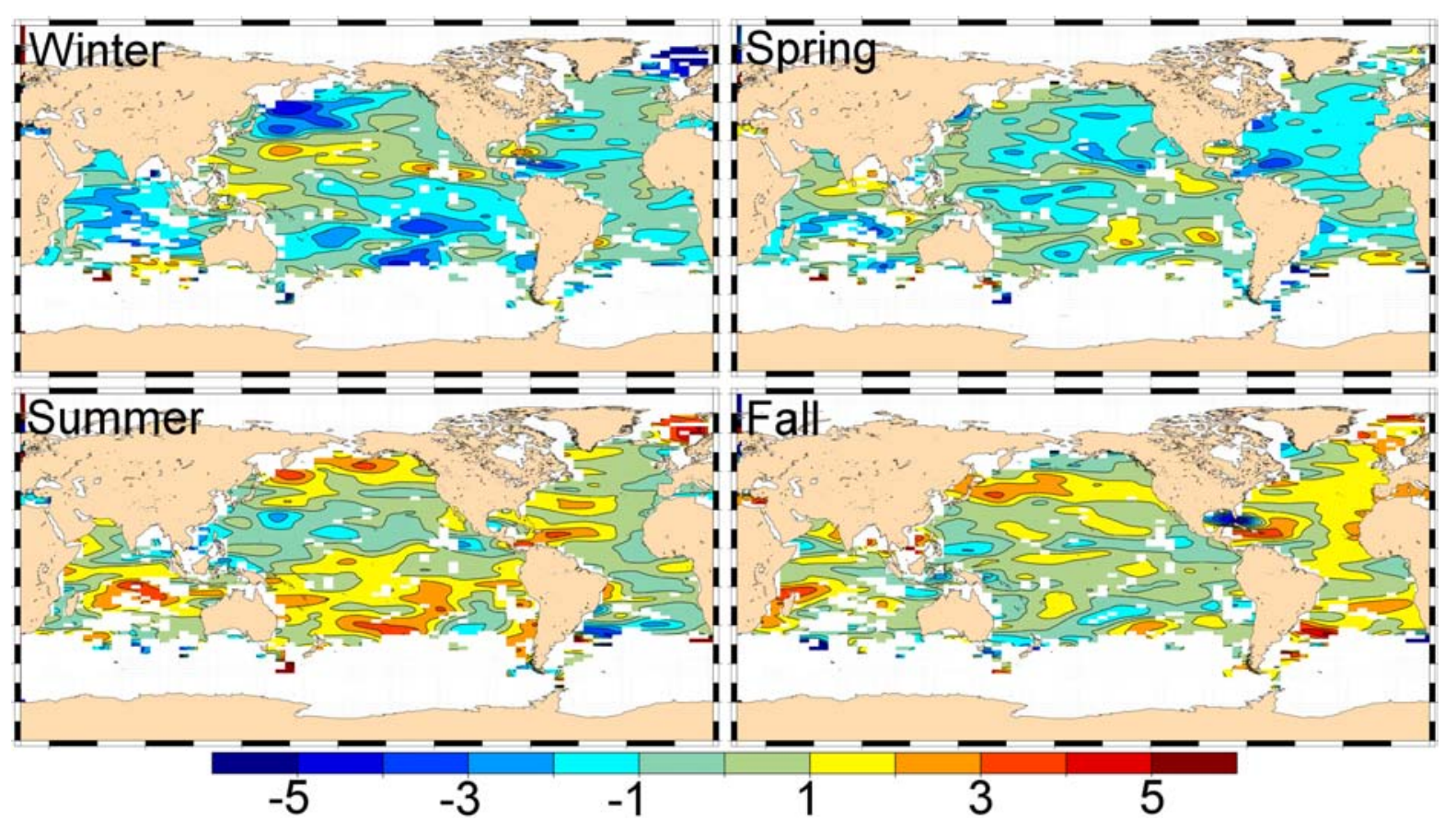

Figure 2: Seasonal variation of the differences between SLA and DHA - Unit : $\mathrm{cm}$. Differences have been calculated in $2^{\circ}$ latitude by $5^{\circ}$ longitude grid boxes and boxes only validated for the four seasons are displayed. 


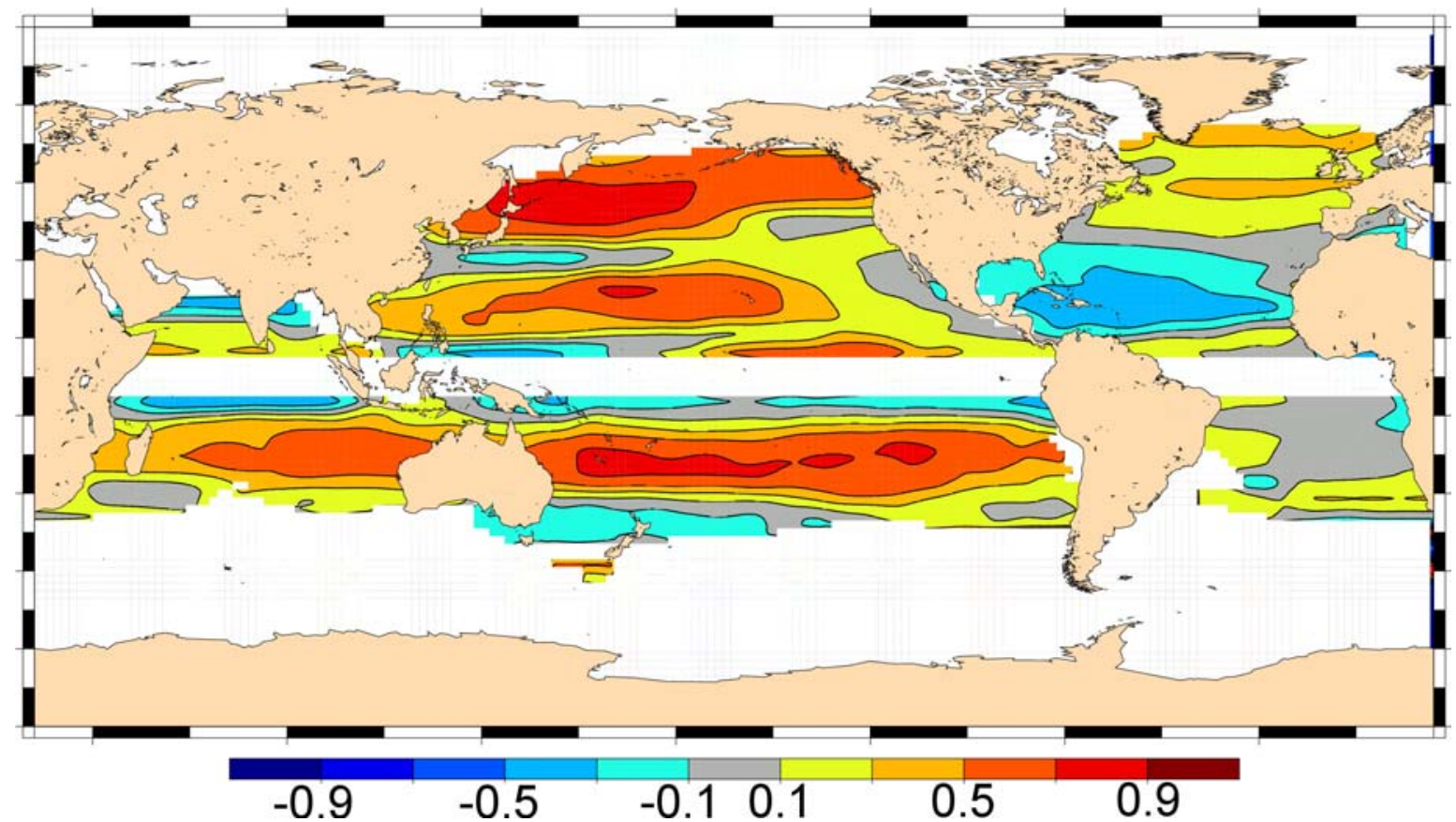

Figure 3: Correlation coefficient between SLA minus DHA signals and Sverdrup transport anomalies. The equatorial region has been masked since the Sverdrup dynamic could not be applied near the equator. Statistics have been calculated on a $2^{\circ} \times 2^{\circ}$ horizontal grid using observations available in $25^{\circ}$ longitude by $5^{\circ}$ latitude radius of influence around each grid point. Boxes with less than 50 observations are masked.

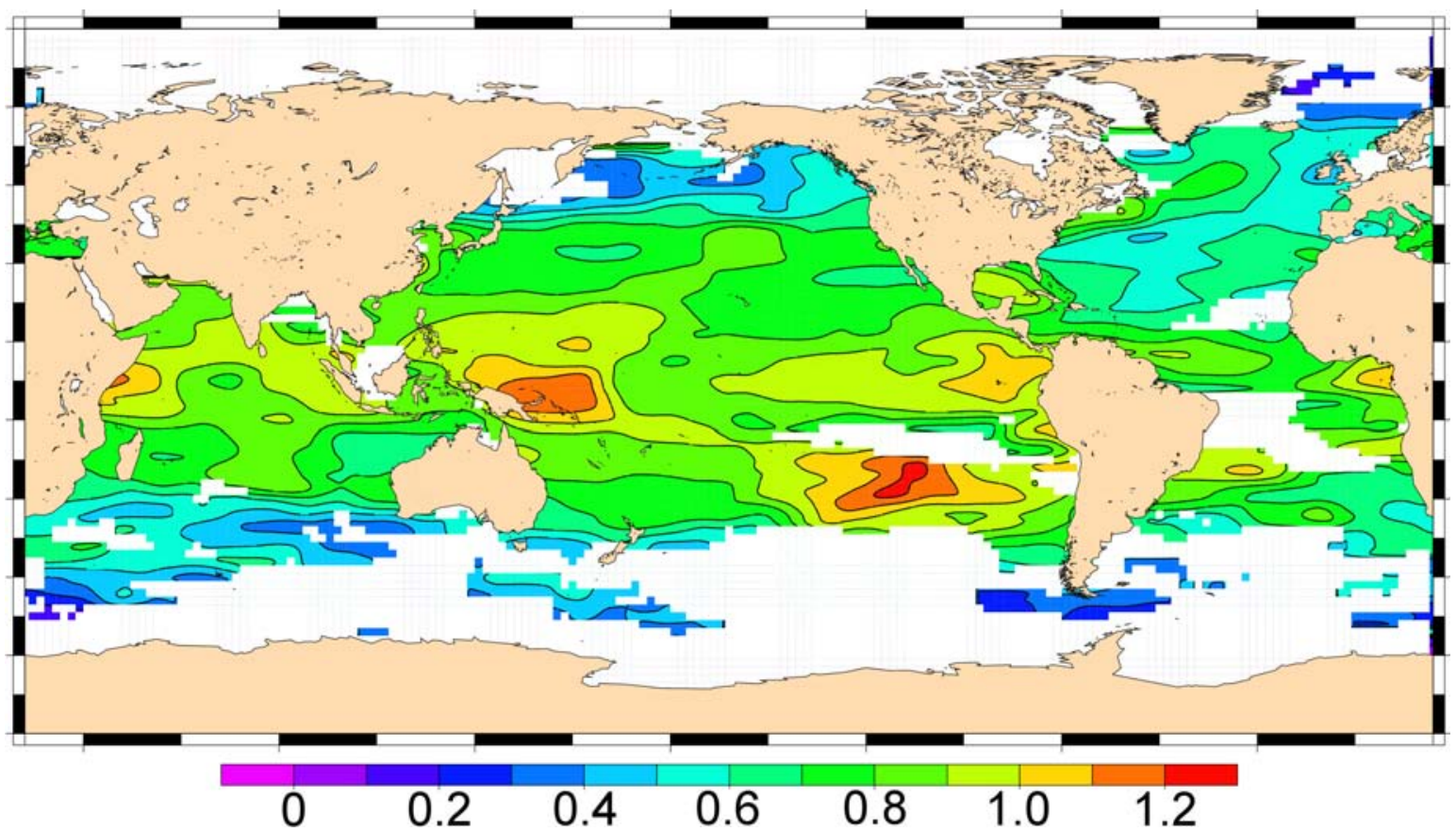

Figure 4: Regression coefficient between SLA and DHA. Statistics have been calculated using the same selection criteria than Figure 1. Additionally, boxes where correlation coefficients between SLA and DHA are lower than 0.4 are masked. 
Auxiliary Material Submission for Paper 2005GL025551R

What can we learn from Global Altimetry/Hydrography comparisons?

Stephanie Guinehut (1), Pierre-Yves Le Traon (2) and Gilles Larnicol (1)

((1) CLS Space Oceanography Division, Ramonville, France; (2) IFREMER, Plouzané, France)

Geophys. Res. Lett., xxx, doi 10.1029/2005GL025551R, 2005.

Introduction

We present six figures as auxiliary material for use by researchers.

The first three figures present time series (from January 1993 to December 2003) of collocated altimeter sea level anomalies (SLA) and dynamic height anomalies (DHA) derived from T and S profiles. The two data sets have been averaged by month and over $10^{\circ}$ bands of latitudes. There is one figure per ocean. The DHA have been calculated using a level of no motion at $700 \mathrm{~m}$ depth and a synthetic climatology as the mean dynamic height. $\mathrm{T}$ and $\mathrm{S}$ profiles are from the ENACT and CORIOLIS data base. SLA are from AVISO delayed-mode products.

The three last figures present time series (from January 1993 to December 2003) of collocated SLA minus DHA signals and Sverdrup transport equivalent height. Again, the two data sets have been averaged by month and over $10^{\circ}$ bands of latitudes. There is one figure per ocean. The Sverdrup transport is calculated from ERS-1/2 and QuickSCAT wind stress fields distributed by CERSAT. The Sverdrup equivalent height has been calculated from the Sverdrup transport using the flowing equation: height $=$ Sverdrup transport $* \mathrm{f} /(\mathrm{gH})$ where $\mathrm{f}$ is the Coriolis parameter, $\mathrm{g}$ the gravitational acceleration and $\mathrm{H}$ the depth of the ocean at each grid point. 
Pacific

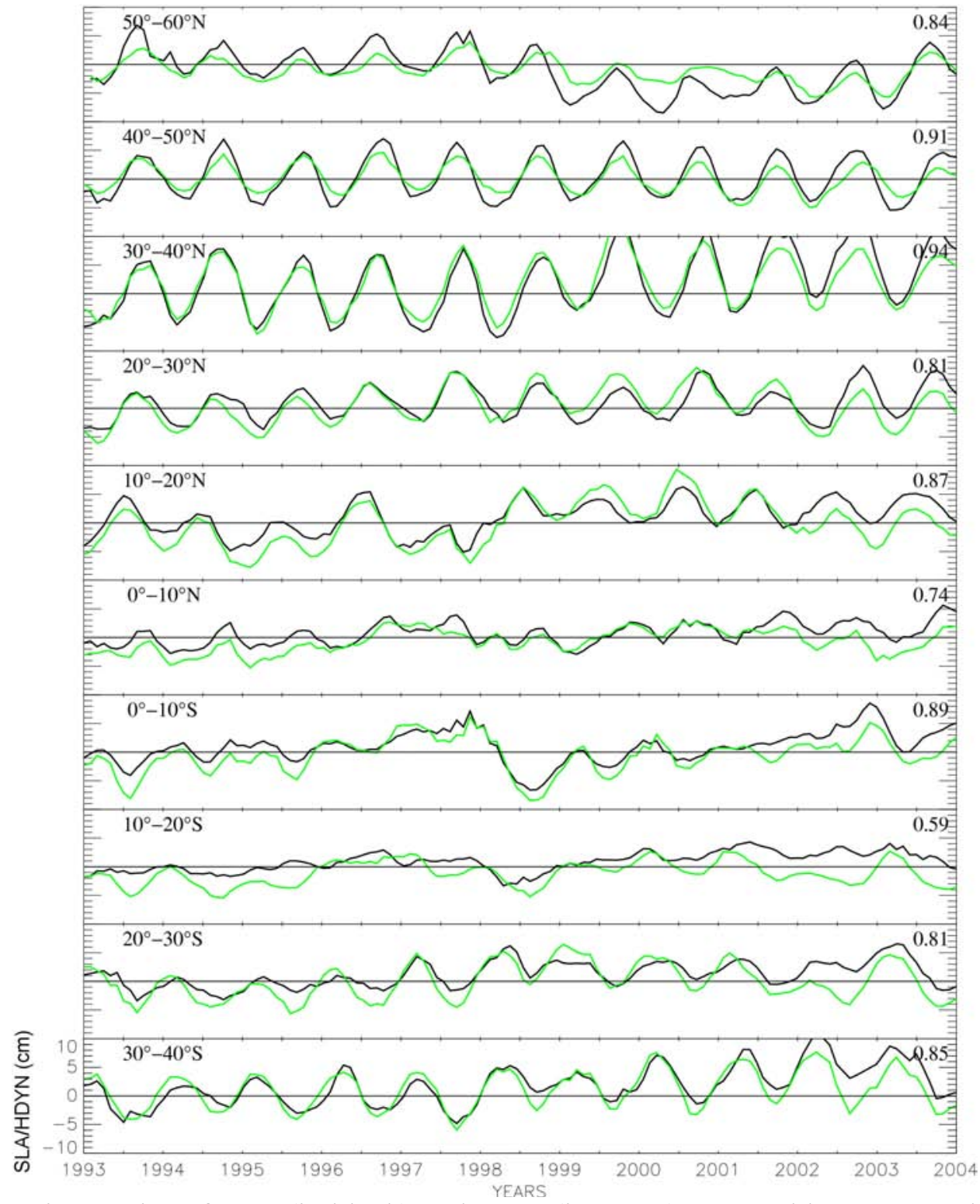

Figure A1. Time series of SLA (in black) and DHA (in green) as monthly means and as spatial averages over $10^{\circ}$ of latitudes for the Pacific Ocean (Unit: $\mathrm{cm}$ ). 


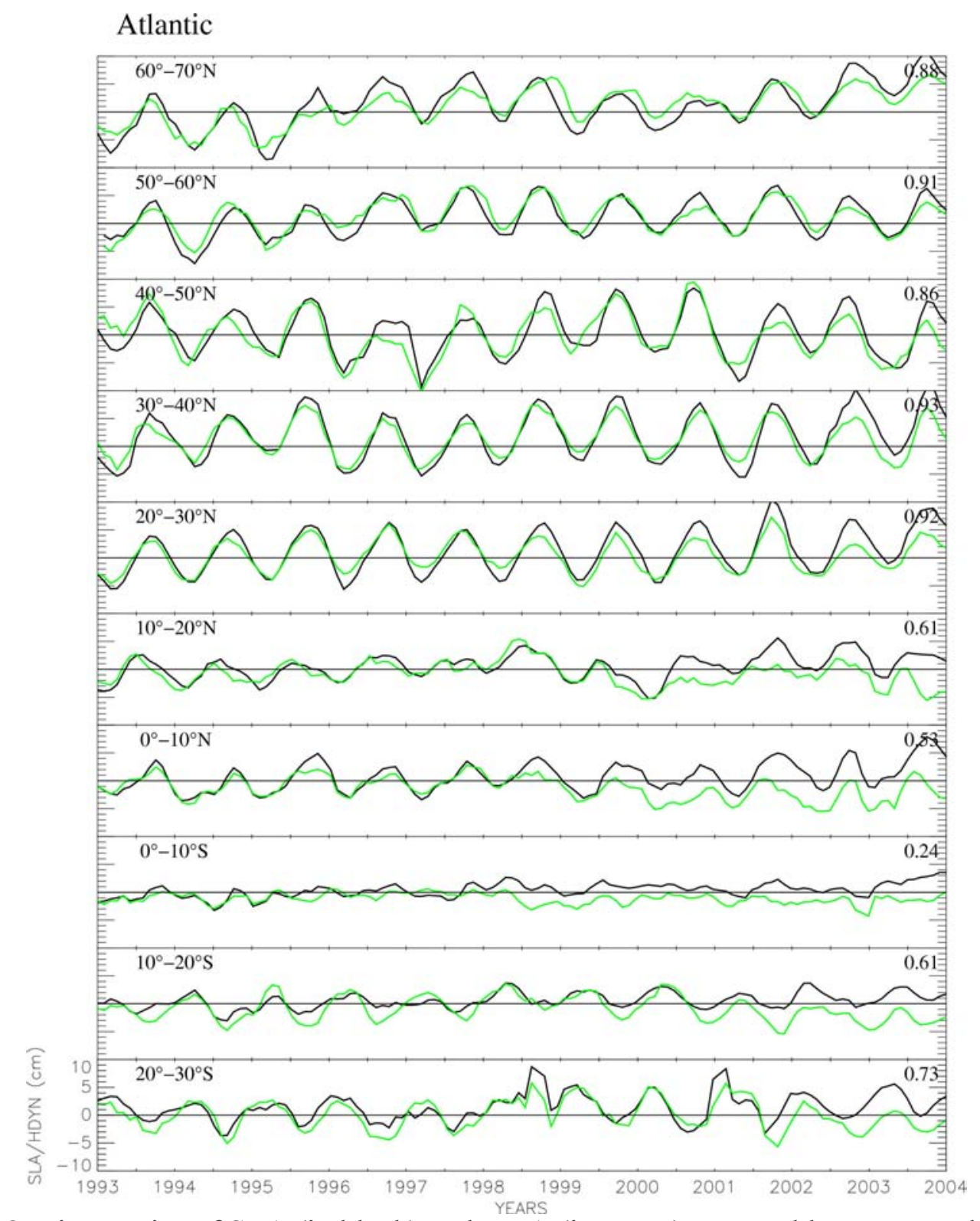

Figure A2. Time series of SLA (in black) and DHA (in green) as monthly means and as spatial averages over $10^{\circ}$ of latitudes for the Atlantic Ocean (Unit: cm). 


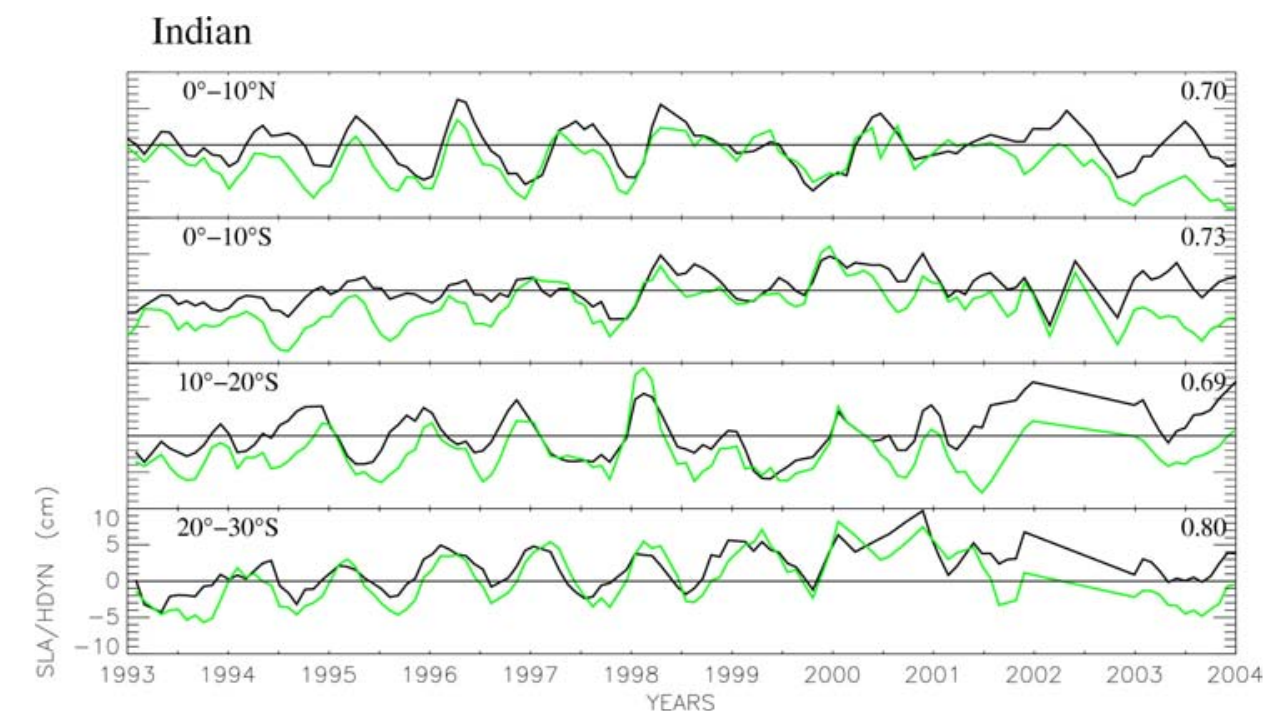

Figure A3. Time series of SLA (in black) and DHA (in green) as monthly means and as spatial averages over $10^{\circ}$ of latitudes for the Indian Ocean (Unit: $\mathrm{cm}$ ). 
Pacific

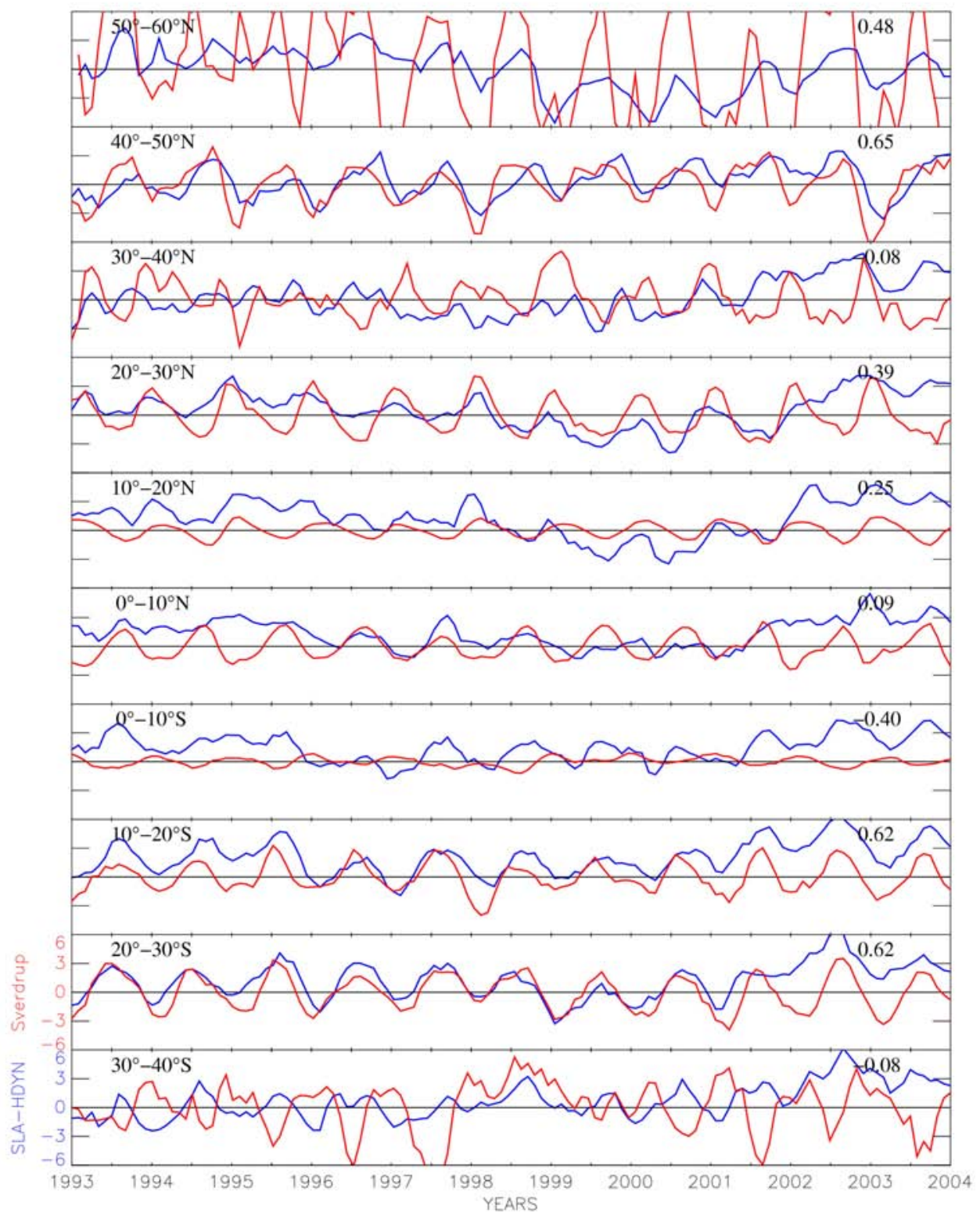

Figure A4. Time series of altimeter SLA minus DHA signals (in blue) and Sverdrup transport equivalent height (in red) as monthly means and as spatial averages over $10^{\circ}$ of latitudes for the Pacific Ocean (Unit: cm). 


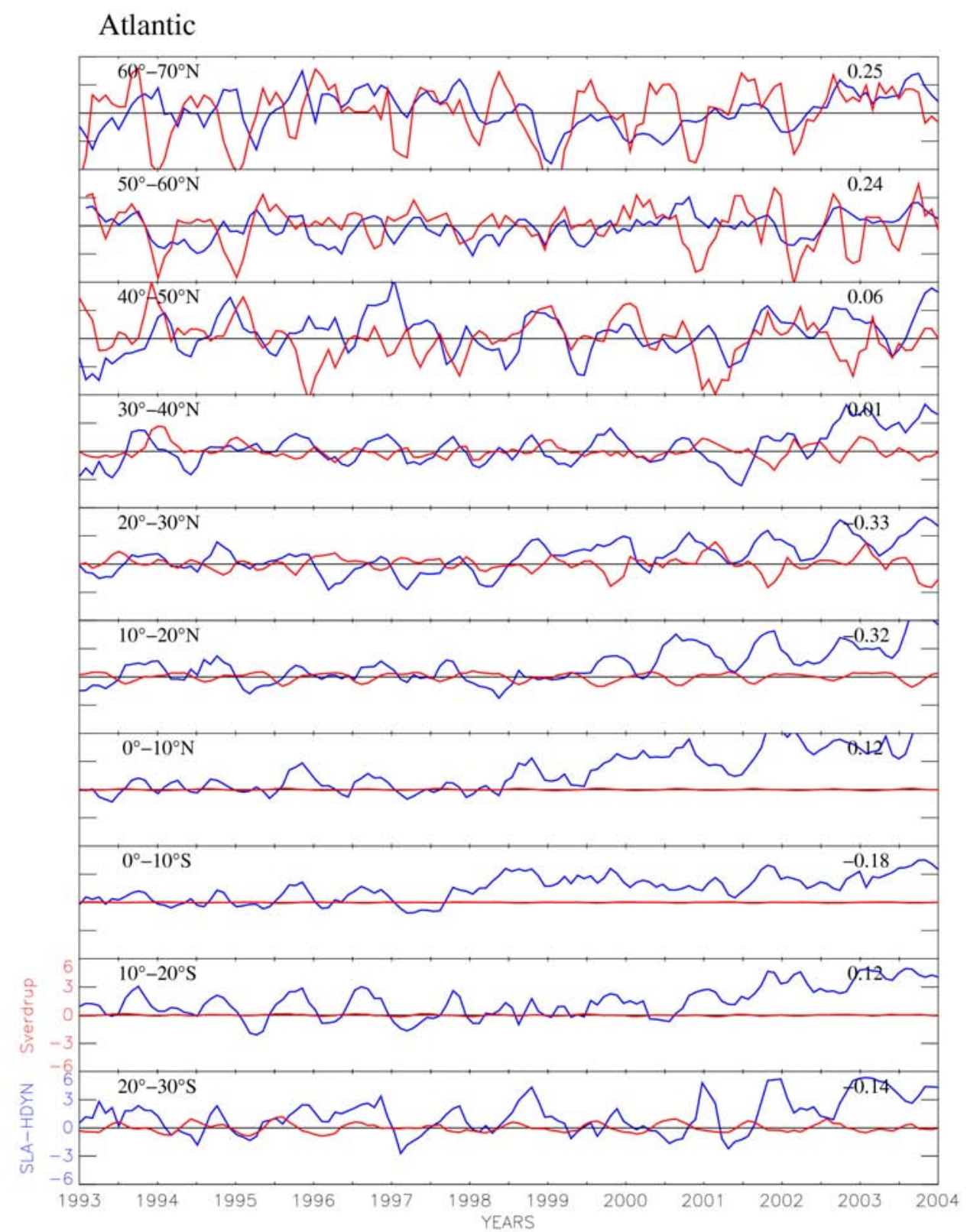

Figure A5. Time series of altimeter SLA minus DHA signals (in blue) and Sverdrup transport equivalent height (in red) as monthly means and as spatial averages over $10^{\circ}$ of latitudes for the Atlantic Ocean (Unit: cm). 


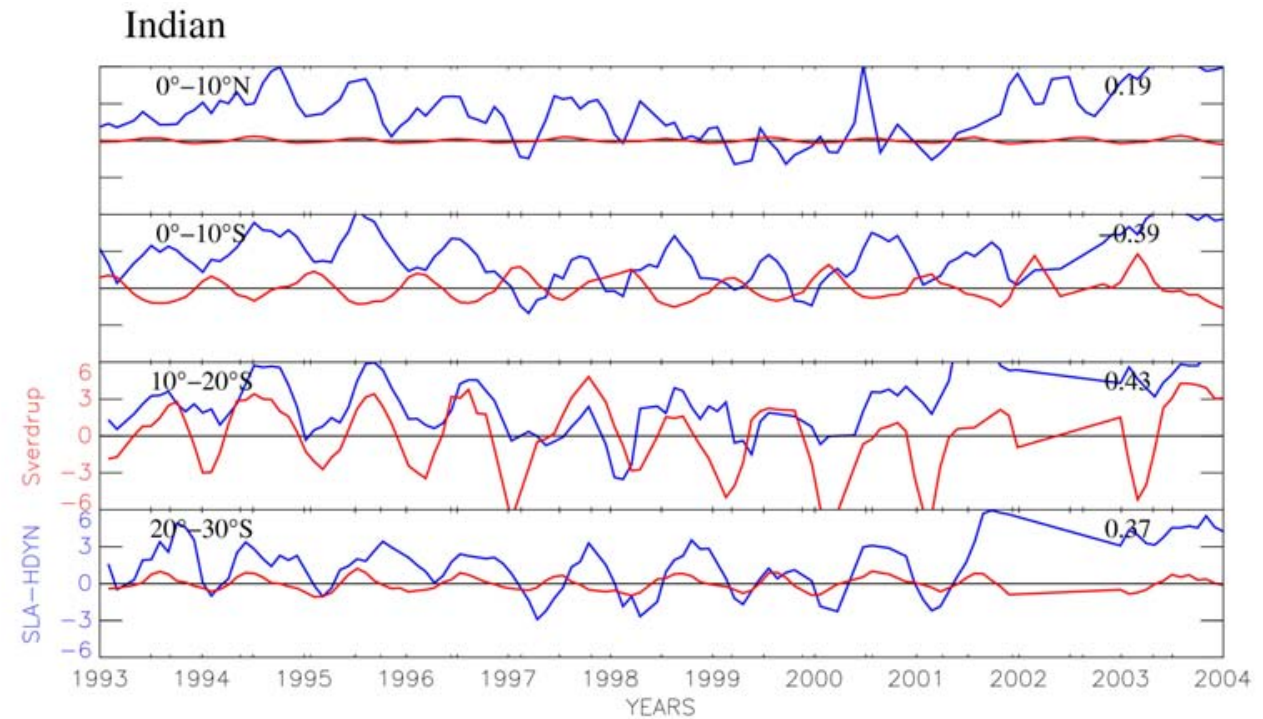

Figure A6. Time series of altimeter SLA minus DHA signals (in blue) and Sverdrup transport equivalent height (in red) as monthly means and as spatial averages over $10^{\circ}$ of latitudes for the Indian Ocean (Unit: cm). 